\title{
Comparison between patient-reported outcomes after enucleation and proton beam radiotherapy for uveal melanomas: a 2-year cohort study
}

\author{
Laura Hope-Stone ${ }^{1,2} \cdot$ Stephen L. Brown ${ }^{1} \cdot$ Heinrich Heimann² ${ }^{2}$ Bertil Damato ${ }^{2,3}$ \\ Received: 26 April 2018 / Revised: 19 February 2019 / Accepted: 4 April 2019 / Published online: 15 April 2019 \\ (c) The Royal College of Ophthalmologists 2019
}

\begin{abstract}
Background Uveal melanomas affect 2-8 per million Europeans each year. Approximately 35\%, are treated by enucleation. Proton beam radiotherapy (PBR) can be an eye-conserving alternative to enucleation for patients who wish to retain the eye. Both treatments have adverse effects, and it is difficult for clinicians and patients to make fully informed choices between them because the relative effects of enucleation and PBR on patient-reported outcomes are unknown.

Methods We compared differential effects of enucleation and PBR on patient-reported outcomes on the European Organisation for Research and Treatment of Cancer Quality of Life Questionnaire-Ophthalmological module (EORTC QLQOPT30) in a consecutive sample of 115 treated patients $\sim 6,12$ and 24 months after diagnosis. Pre-treatment demographic variables, unrelated health problems, vision in the fellow eye, tumour characteristics and prognosis for metastatic disease were statistically controlled.

Results Patients treated by enucleation experienced greater functional problems at 6 months, which abated at 12 and 24 months $(P=0.020)$. PBR patients reported greater impairments of central and peripheral vision $(P=0.009)$ and reading difficulties $(P=0.002)$ over 24 months. Treatment modality did not influence difficulty in driving $(P=0.694)$, ocular irritation $(P=0.281)$, headaches $(P=0.640)$, appearance concerns $(P=0.187)$ or worry about recurrence $(P=0.899)$.

Conclusions When making treatment decisions, it is important that patients and clinicians consider long-standing difficulties of visual impairment associated with PBR and temporary 6-month difficulties in activities related to depth perception associated with enucleation.
\end{abstract}

\section{Introduction}

Uveal melanoma (UM) is a rare cancer of the eye that affects 2-8 individuals per million Caucasian people per year in Europe, depending on ocular pigmentation [1]. UM treatments aim to preserve the eye with useful vision. Plaque radiotherapy is a preferred treatment in many centres

$\triangle$ Laura Hope-Stone

ldhs@liverpool.ac.uk

1 Institute of Psychology, Health \& Society, University of Liverpool, Liverpool L69 3GB, UK

2 Liverpool Ocular Oncology Centre, Royal Liverpool and Broadgreen University Hospital, NHS Trust, Prescot St, Liverpool L7 8XP, UK

3 Ocular Oncology Service, University of California, San Francisco, CA 94143-0730, USA
[2] but not recommended in some centres where tumours are large or close to the optic disc. In these cases, enucleation can be considered [3, 4].

Enucleation is performed in $\sim 35 \%$ of patients [5]. Adverse outcomes are loss of binocular vision, potential socket-related complications and phantom symptoms such as visual sensations [6]. Proton beam radiotherapy (PBR) is sometimes an alternative to enucleation when patients wish to retain the eye. PBR preserves the eye but carries risks of neovascular glaucoma, radiation retinopathy, papillopathy, retinal detachment, local tumour recurrence $[7,8]$ and collateral damage to extraocular structures such as eyelids, lacrimal gland and tear ducts [9].

Decisions of whether to preserve the eye or not are not always clinically clear cut. In these cases, careful consideration of the consequences of treatments are necessary for effective treatment decisions [4]. Patients may prefer to retain the eye, although doing so confers clinical disadvantage, or prefer enucleation in the absence of decisive 
clinical need [4, 10]. To make informed decisions, clinicians and patients need to understand potential consequences of enucleation and PBR.

Objective probabilities of adverse side effects, local and distant recurrence and overall survival are known [3, 11, 12] and patients are routinely informed of these [4]. To our knowledge, no study has examined how enucleation and PBR influence patients' experiences of adverse treatment outcomes. Loss of binocular vision after enucleation causes a range of problems associated with distance perception, whereas prostheses can cause irritation, discomfort, pain and appearance dissatisfaction [13, 14]. Adverse patient-reported outcomes of PBR can include progressive visual impairments, linked to known central and peripheral visual loss and the presence of unwanted visual sensations, and cause discomfort owing to tissue damage to extraocular structures [9]. These outcomes are associated with the likelihood of developing longterm clinically relevant anxiety and depression in UM patients [15].

It is unknown whether enucleation and PBR differentially affect worry about cancer recurrence (WREC). In our unit, that treats between 200 to 250 new patients with UM per annum, some patients worry about local recurrence and wish to reduce this worry through enucleation [4]. Studies in other cancers confirm that patients sometimes request radical surgeries to remove organs because they fear local cancer recurrence [16]. WREC is linked to clinically relevant anxiety [15], thus clinicians may regard reducing patients' fears of recurrence as a valid consideration for treatment choice [17]. However, there is as yet no evidence that enucleation reduces fear to a greater extent than PBR in UM patients.

Our aim was to identify any differential effects of treatment modality (enucleation versus PBR) on patientreported outcomes of ocular irritation, visual impairment, headaches, appearance concerns, functional problems, reading and driving problems, and WREC. We compared treatment modalities $\sim 6,12$ and 24 months after diagnosis (Some data used in this report are the same of those used by Damato et al. [18]. The Damato study focusses on a broader question pertaining to trajectories of patientreported outcomes over time after radiotherapy, whereas this paper addresses a specific clinical question pertaining to adverse effects of enucleation compared to PBR). As treatment decisions are influenced by patient and tumour characteristics, we statistically adjusted age, gender, presence or absence of unrelated health problems, visual acuity in the fellow eye at diagnosis, tumour size, and prognosis for metastatic disease. Poor prognosis for metastatic disease was defined by the presence of monosomy 3 (loss of one copy of chromosome 3 ) in tumour cells.

\section{Methods}

This study was approved as a clinical audit by the Health Research Authority North West-Liverpool Central Ethics Committee (03/06/072/A) and was conducted in accordance with the Declaration of Helsinki.

\section{Design}

Prospective design with patient-reported outcome measures taken at 6, 12 and 24 months after diagnosis, in nonrandomised consecutive samples of enucleated or PBR patients with clinical and demographic variables statistically controlled. As plaque radiotherapy was not considered to be clinically viable owing to tumour characteristics or position, these patients were excluded so as not to dilute the analysis. Data were taken from a larger project, thus no power analyses were made for this specific investigation [19].

\section{Participants}

Informed consent was sought from a consecutive series of adult patients treated at the Liverpool Ocular Oncology Centre (LOOC) for posterior UM (i.e., choroid and ciliary body) between 1st April 2008 and 31st December 2011. We excluded non-enucleation or non PBR treatments and patients with tumours that involved the iris. The final sample consisted of patients who provided data at each of the three follow-ups.

Diagnosis and treatment of UM was based on clinical and tumour characteristics, as described by Damato and Heimann [4]. Where tumours were relatively small or medium sized (thickness $<6 \mathrm{~mm}$ diameter $<18 \mathrm{~mm}$ ) or not close to the optic disc, plaque radiotherapy was the preferred treatment. Enucleation was considered for larger tumour size and PBR for tumours with optic disc involvement or larger tumours (thickness $>6 \mathrm{~mm}$ ) where patients wished to keep the eye and the tumour diameter was $<18 \mathrm{~mm}$. Patient preferences for or against particular procedures were considered in treatment selection.

\section{Data collected}

At the time of diagnosis, patients were asked if they were willing to participate in an audit to examine long-term patient-reported outcomes of treatment. All patients who gave written consent were posted the self-report questionnaire with enclosed postage-paid envelopes addressed to the audit team 6, 12 and 24 months following diagnosis.

Sociodemographic and clinical characteristics of the sample were collected from patients' clinical records. These were age, gender, patient-identified unrelated health problems, relationship status, employment status, whether the 
Table 1 EORTC QLQ- OPT30 subscales

\begin{tabular}{|c|c|c|c|c|c|}
\hline \multirow[t]{2}{*}{ Scale } & \multirow[t]{2}{*}{ Example item } & \multirow[t]{2}{*}{ No of items } & \multicolumn{3}{|c|}{ Cronbach's Alpha } \\
\hline & & & $6 \mathrm{mths}$ & 12 mths & 24 mths \\
\hline Ocular irritation & Were you troubled by any discharge from your treated eye? & 6 & 0.71 & 0.73 & 0.77 \\
\hline Vision impairment & Were you troubled by any defects in your side vision? & 4 & 0.69 & 0.73 & 0.71 \\
\hline Functional problems & Did you have difficulty seeing steps or pavements? & 6 & 0.92 & 0.92 & 0.93 \\
\hline $\begin{array}{l}\text { Worry about recurrence (local and } \\
\text { metastatic) }\end{array}$ & $\begin{array}{l}\text { Were you worried about the tumour recurring in the } \\
\text { treated eye? }\end{array}$ & 3 & 0.87 & 0.85 & 0.85 \\
\hline Appearance concerns & Has your appearance bothered you'? & 2 & $0.38^{\mathrm{a}}$ & $0.54^{\mathrm{a}}$ & $0.54^{\mathrm{a}}$ \\
\hline Driving difficulties & Did you have difficulty driving in the dark? & 2 & $0.61^{\mathrm{a}}$ & $0.60^{\mathrm{a}}$ & $0.48^{\mathrm{a}}$ \\
\hline Headaches & Did you have headaches? & 1 & & NA & \\
\hline Reading & Did you have difficulty reading because of your vision? & 1 & & NA & \\
\hline
\end{tabular}

${ }^{\mathrm{a}}$ Correlation coefficients used for two-item scales

right or left eye was affected, vision in the fellow eye at diagnosis as $\log$ MAR scores, tumour origin (choroid or ciliary body), tumour size (ultrasound height and largest basal diameter) and treatment modality. Prognostication was based on chromosome 3 status as the primary determinant of life expectancy $[12,20]$ and was categorised as: monosomy 3, disomy 3 (i.e., normal maternal and paternal copies of chromosome 3) and unknown (comprising patients who did not wish to be tested, tumours were small, and those whose genetic test failed). For patients undergoing PBR, prognostic biopsies were usually performed on the last day of treatment.

Following treatment, symptoms and functional problems were measured using the European Organisation for Research and Treatment for Cancer Ophthalmic Oncology Quality of Life questionnaire module (EORTC QLQOPT30) [21] designed specifically for UM patients and validated in UM samples [22]. Subscales specific to enucleation or PBR were not used. Details of the subscale items are shown in Table 1.

\section{Statistical analysis}

\section{Sample retention}

Multivariate logistic regression was used to test whether baseline age, sex, health problems, chromosome 3 status, $\log$ MAR scores for the fellow eye, tumour thickness, and largest basal diameter and 6-month EORTC QLQOPT30 scores predicted retention in the sample at 12 and 24 months.

\section{Outcomes for each treatment modality}

Data were normally distributed and showed homogeneity of variance. First, mixed-model analyses of variance (MANOVAs) were used to predict EORTC QLQ- OPT30 scores at 6, 12 and 24 months. Enucleation versus PBR treatment was a two-group predictor variable. To prevent confounding by pre-treatment differences between treatment groups, these analyses were repeated with statistical adjustment using age, sex, health problems, chromosome 3 status, logMAR scores for the fellow eye, tumour thickness, and largest basal diameter as covariates. Chromosome 3 status was coded into two binomial variables; the first denoting monosomy 3 or not (including those with disomy 3 and those whose chromosome 3 status was unknown), the second denoting disomy 3 or not (monosomy 3 and unknown).

\section{Results}

\section{Sample description and retention analysis}

Three hundred and sixty patients were approached to participate. Of these, 194 returned questionnaires at 6 months, 155 at 12 months and 132 at 24 months. One hundred and fifteen returned questionnaires at all three time points and were included (59.3\% retention). Sixty-six patients were treated by enucleation and 49 treated by PBR. Demographic and clinical characteristics for each treatment group are presented in Table 2. Monosomy 3 was more prevalent in enucleated patients. The logistic regression predicting 24 month retention from 6-month study variables was not significant $\left(\chi^{2}=15.23\right.$, Nagelkerke $\mathrm{R}^{2}=1.06, \quad d f=14$, $p=.294)$, showing no bias in retention.

\section{Outcomes by treatment modality}

Estimated marginal means and results of unadjusted and adjusted significance tests for outcome variables at 6,12 and 24 months after diagnosis are shown in Table 3 (We examined whether treatment modality effects were moderated or accentuated by covariates. We did not observe clear 
Table 2 Sample characteristics for the full sample and by treatment modality

\begin{tabular}{|c|c|c|c|c|c|c|c|}
\hline \multirow{2}{*}{$\begin{array}{l}\text { Variable } \\
\text { Median age (range) }\end{array}$} & \multirow[t]{2}{*}{ Category } & \multicolumn{2}{|c|}{ Full sample $N=115$} & \multicolumn{2}{|c|}{$\begin{array}{l}\text { Enucleation } N=66 \\
(57.4 \%)\end{array}$} & \multicolumn{2}{|c|}{$\begin{array}{l}\text { Proton beam } N=49 \\
(42.6 \%)\end{array}$} \\
\hline & & \multicolumn{2}{|c|}{$62.5(54.6-71.8)$} & \multicolumn{2}{|c|}{$65.2(56.2-72.8)$} & \multicolumn{2}{|c|}{$62.5(51.5-70.5)$} \\
\hline & & $N$ & $\%$ & $N$ & $\%$ & $N$ & $\%$ \\
\hline \multirow[t]{2}{*}{ Sex } & Male & 56 & 48.7 & 32 & 48.5 & 24 & 49 \\
\hline & Female & 59 & 51.3 & 34 & 51.5 & 25 & 51 \\
\hline \multirow[t]{5}{*}{ Marital status } & $\begin{array}{l}\text { Married/living with } \\
\text { partner }\end{array}$ & 86 & 74.8 & 44 & 66.7 & 42 & 85.7 \\
\hline & Divorced/separated & 12 & 10.4 & 10 & 15.2 & 2 & 4.1 \\
\hline & Widowed & 11 & 9.6 & 9 & 13.6 & 2 & 4.1 \\
\hline & Single & 4 & 3.5 & 2 & 3 & 2 & 4.1 \\
\hline & Not recorded & 2 & 1.7 & 1 & 1.5 & 1 & 2 \\
\hline \multirow[t]{5}{*}{ Employment status } & Employed & 36 & 31.3 & 18 & 27.3 & 18 & 36.6 \\
\hline & Homemaker & 4 & 3.5 & 1 & 1.5 & 3 & 6.1 \\
\hline & Retired & 56 & 48.7 & 34 & 51.5 & 22 & 44.9 \\
\hline & $\begin{array}{l}\text { Long-term sick/ } \\
\text { medically retired }\end{array}$ & 10 & 8.7 & 7 & 10.6 & 3 & 6.1 \\
\hline & Not specified & 9 & 7.8 & 6 & 9.1 & 3 & 6.1 \\
\hline \multirow[t]{3}{*}{ Health problems } & Yes & 73 & 63.5 & 44 & 66.7 & 29 & 59.2 \\
\hline & No & 40 & 34.8 & 20 & 30.3 & 20 & 40.8 \\
\hline & Not specified & 2 & 1.7 & 2 & 3 & 0 & 0 \\
\hline \multirow[t]{2}{*}{ Eye } & Right & 58 & 50.4 & 35 & 53 & 23 & 46.9 \\
\hline & Left & 57 & 49.6 & 31 & 47 & 26 & 53.1 \\
\hline \multirow[t]{2}{*}{ Tumour origin } & Choroid & 103 & 89.6 & 60 & 90.9 & 43 & 87.8 \\
\hline & Ciliary body & 12 & 10.4 & 6 & 9.1 & 6 & 12.2 \\
\hline \multirow{2}{*}{$\begin{array}{l}\text { Visual acuity: fellow } \\
\text { eye at diagnosis }\end{array}$} & $6 / 5-6 / 12$ & 112 & 97.4 & 63 & 95.5 & 49 & 100 \\
\hline & $6 / 18-6 / 60$ & 3 & 2.6 & 3 & 4.5 & 0 & 0 \\
\hline \multirow[t]{2}{*}{ Prognostication } & $\begin{array}{l}\text { Monosomy } 3 \\
\text { confirmed }\end{array}$ & 55 & 47.8 & 45 & 68.2 & 10 & 20.4 \\
\hline & $\begin{array}{l}\text { Monosomy } 3 \text { not } \\
\text { confirmed }\end{array}$ & 60 & 52.2 & 21 & 31.8 & 39 & 79.6 \\
\hline \multirow{2}{*}{$\begin{array}{l}\text { Mean tumour size: } \mathrm{mm} \\
\text { (SD) range }\end{array}$} & Ultrasound height & \multicolumn{2}{|c|}{5.59 (3.74) $0.6-14.8$} & \multicolumn{2}{|c|}{7.25 (3.65) $0.8-14.8$} & \multicolumn{2}{|c|}{3.38 (2.55) $0.6-10.3$} \\
\hline & $\begin{array}{l}\text { Largest basal } \\
\text { diameter }\end{array}$ & \multicolumn{2}{|c|}{13.04 (4.56) $0.99-20.5$} & \multicolumn{2}{|c|}{15.20 (3.55) 6.5-20.5 } & \multicolumn{2}{|c|}{10.17 (4.18) 0.99-18.9 } \\
\hline
\end{tabular}

patterns of moderation or accentuation of treatment effects.). Enucleation was associated with greater ocular irritation, appearance concerns, and functional problems, with treatment differences in functional problems significantly reducing over time. Unadjusted means show PBR to be associated with greater reading difficulties scores.

Statistical adjustment changed statistical significance in some analyses. Enucleated patients experienced more functional problems at 6 months, but these reduced linearly over 12 and 24 months $(\mathrm{F}=4.00, d f=2 p=0.020)$ with Bonferroni post-hoc tests showing a significant reduction between 6- and 24- month observations but not between adjacent observations. PBR patients experienced more visual impairment and had more difficulty in reading over all time points than enucleated patients. No differences between treatment modalities were apparent at any time point for ocular irritation, headaches, appearance concerns, driving difficulties or WREC.

\section{Discussion}

To our knowledge, this study is the first to document differential effects of enucleation and PBR on patient-reported outcomes. Enucleation was initially associated with greater functional problems, which lessened after 6 months, whereas patients treated by PBR reported greater visual impairment and reading difficulties than those treated by 
Table 3 Adjusted and unadjusted means and SEs for the full sample and by treatment modality

\begin{tabular}{|c|c|c|c|c|c|c|c|}
\hline \multirow[t]{2}{*}{ Outcome } & \multicolumn{2}{|c|}{ Sample mean (SE) } & \multicolumn{2}{|l|}{ Enucleation } & \multicolumn{2}{|l|}{ Proton Beam } & \multirow[t]{2}{*}{ Significance $\$$} \\
\hline & Adjusted & Unadjusted & Adjusted & Unadjusted & Adjusted & Unadjusted & \\
\hline Ocular irritation & $N=112$ & $N=113$ & $N=64$ & $N=65$ & $N=48$ & $N=48$ & \\
\hline 6 months & $1.74(0.057)$ & $1.74(0.057)$ & $1.79(0.088)$ & $1.79(0.075)$ & $1.70(0.107)$ & $1.69(0.087)$ & Time $\mathrm{F}=0.3 .75^{*}$ \\
\hline 12 months & $1.73(0.054)$ & $1.72(0.053)$ & $1.78(0.083)$ & $1.82(0.069)$ & $1.68(0.101)$ & $1.62(0.081)$ & Treat $\mathrm{F}=1.17$ \\
\hline 24 months & $1.72(0.054)$ & $1.74(0.054)$ & $1.87(0.083)$ & $1.87(0.070)$ & $1.62(0.101)$ & $1.60(0.081)$ & $\mathrm{T} \times \mathrm{T} \mathrm{F}=1.04$ \\
\hline Visual impairment & $N=109$ & $N=110$ & $N=62$ & $N=63$ & $N=47$ & $N=47$ & \\
\hline 6 months & $1.47(0.049)$ & $1.46(0.050)$ & $1.34(0.076)$ & $1.43(0.066)$ & $1.60(0.092)$ & $1.49(0.076)$ & Time $\mathrm{F}=0.18$ \\
\hline 12 months & $1.52(0.062)$ & $1.50(0.063)$ & $1.29(0.097)$ & $1.42(0.082)$ & $1.74(0.116)$ & $1.57(0.095)$ & Treat $\mathrm{F}=7.21^{*}$ \\
\hline 24 months & $1.49(0.054)$ & $1.47(0.056)$ & $1.32(0.095)$ & $1.42(0.073)$ & $1.66(0.103)$ & $1.52(0.085)$ & $\mathrm{T} \times \mathrm{T} \mathrm{F}=0.80$ \\
\hline Reading & $N=113$ & $N=114$ & $N=64$ & $N=65$ & $N=49$ & $N=49$ & \\
\hline 6 months & $1.83(0.079)$ & $1.82(0.083)$ & $1.48(0.123)$ & $1.69(0.109)$ & $2.17(0.147)$ & $1.94(0.126)$ & Time $\mathrm{F}=0.40$ \\
\hline 12 months & $1.73(0.078)$ & $1.74(0.083)$ & $1.45(0.121)$ & $1.55(0.109)$ & $2.00(0.145)$ & $1.92(0.125)$ & Treat $F=10.03^{*}$ \\
\hline 24 months & $1.79(0.078)$ & $1.79(0.083)$ & $1.54(0.121)$ & $1.68(0.105)$ & $2.03(0.144)$ & $1.90(0.121)$ & $\mathrm{T} \times \mathrm{T} \mathrm{F}=0.52$ \\
\hline Functional problems & $N=113$ & $N=114$ & $N=64$ & $N=65$ & $N=49$ & $N=49$ & \\
\hline 6 months & $1.85(0.059)$ & $1.84(0.062)$ & $2.06(0.092)$ & $2.18(0.081)$ & $1.63(0.110)$ & $1.50(0.093)$ & Time $F=.93$ \\
\hline 12 months & $1.79(0.059)$ & $1.79(0.064)$ & $1.90(0.092)$ & $2.03(0.084)$ & $1.68(0.110)$ & $1.54(0.096)$ & Treat $F=2.75$ \\
\hline 24 months & $1.81(0.062)$ & $1.82(0.065)$ & $1.85(0.096)$ & $1.97(0.085)$ & $1.76(0.114)$ & $1.64(0.098)$ & $\mathrm{T} \times \mathrm{T} \mathrm{F}=4.0^{*}$ \\
\hline Appearance concerns & $N=112$ & $N=113$ & $N=64$ & $N=65$ & $N=48$ & $N=48$ & \\
\hline 6 months & $1.38(0.060)$ & $1.34(0.060)$ & $1.41(0.093)$ & $1.50(0.078)$ & $1.35(0.060)$ & $1.24(0.091)$ & Time $\mathrm{F}=0.71$ \\
\hline 12 months & $1.32(0.052)$ & $1.33(0.054)$ & $1.46(0.081)$ & $1.49(0.071)$ & $1.18(0.052)$ & $1.17(0.082)$ & Treat $\mathrm{F}=1.77$ \\
\hline 24 months & $1.32(0.057)$ & $1.32(0.057)$ & $1.42(0.087)$ & $1.44(0.075)$ & $1.22(0.057)$ & $1.21(0.087)$ & $\mathrm{T} \times \mathrm{T} \mathrm{F}=1.42$ \\
\hline Headaches & $N=110$ & $N=111$ & $N=63$ & $N=64$ & $N=47$ & $N=47$ & \\
\hline 6 months & $1.60(0.082)$ & $1.60(0.083)$ & $1.58(0.127)$ & $1.59(0.108)$ & $1.62(0.155)$ & $1.60(0.126)$ & Time $\mathrm{F}=0.56$ \\
\hline 12 months & $1.61(0.081)$ & $1.60(0.082)$ & $1.50(0.125)$ & $1.52(0.107)$ & $1.72(0.151)$ & $1.68(0.125)$ & Treat $\mathrm{F}=0.22$ \\
\hline 24 months & $1.48(0.76)$ & $1.47(9.07)$ & $1.49(0.117)$ & $1.52(0.101)$ & $1.48(0.142)$ & $1.43(0.118)$ & $\mathrm{T} \times \mathrm{T} \mathrm{F}=0.79$ \\
\hline Driving difficulties & $N=73$ & $N=73$ & $N=41$ & $N=41$ & $N=32$ & $N=32$ & \\
\hline 6 months & $1.56(0.063)$ & $1.55(0.064)$ & $1.56(0.099)$ & $1.66(0.085)$ & $1.57(0.117)$ & $1.44(0.096)$ & Time $\mathrm{F}=0.27$ \\
\hline 12 months & $1.60(0.069)$ & $1.60(0.074)$ & $1.60(0.108)$ & $1.66(0.098)$ & $1.61(0.127)$ & $1.53(0.110)$ & Treat $F=0.16$ \\
\hline 24 months & $1.72(0.067)$ & $1.70(0.070)$ & $1.64(0.106)$ & $1.78(0.093)$ & $1.80(0.125)$ & $1.63(0.105)$ & $\mathrm{T} \times \mathrm{T} \mathrm{F}=0.45$ \\
\hline Worry about recurrence & $N=112$ & $N=113$ & $N=64$ & $N=65$ & $N=48$ & $N=48$ & \\
\hline 6 months & $2.45(0.085)$ & $2.44(0.089)$ & $2.40(0.131$ & $2.53(0.116)$ & $2.49(0.159)$ & $2.35(0.134)$ & Time $F=0.33$ \\
\hline 12 months & $2.18(0.076)$ & $2.19(0.081)$ & $2.20(0.118)$ & $2.28(0.106)$ & $2.17(0.144)$ & $2.10(0.123)$ & Treat $\mathrm{F}=0.02$ \\
\hline 24 months & $2.10(0.077)$ & $2.09(0.081)$ & $2.09(0.120)$ & $2.15(0.106)$ & $2.10(0.145)$ & $2.04(0.123)$ & $\mathrm{T} \times \mathrm{T} \mathrm{F}=0.19$ \\
\hline
\end{tabular}

${ }^{\$}$ F-ratio statistics for the adjusted timextreatment analyses. ${ }^{*} p<0.05$

enucleation. Treatment modality did not influence difficulty in driving, ocular irritation, headaches, appearance concerns or WREC. Our findings will allow clinicians to better understand how patients are likely to be affected by consequences of enucleation relative to $\mathrm{PBR}$, and to inform patients accordingly.

Findings are consistent with known clinical effects of enucleation and PBR. Enucleation eliminates binocular vision, creating difficulties with depth perception [23]. The functional problems scale is weighted toward tasks requiring depth perception, such as judging distances, pouring drinks and using stairs. Thus, it is unsurprising that enucleated patients reported greater functional problems. Relative functional improvement over 24 months suggests that patients either developed compensatory strategies, such as using alternative cues to judge distance, or changed daily routines, such as avoiding distance perception tasks [24, 25]. After PBR, patients experienced visual impairments and reading difficulties over 24 months. This is consistent with reports of lower visual acuity and greater visual interference $[3,8,9]$.

Treatment modality had little relative effect on ocular irritation, headaches or driving difficulties. It is not feasible to compare our patients to those who had neither 
enucleation nor PBR (owing to large initial differences in patient and tumour characteristics). Thus, we do not know whether equivalence between treatment modalities occurs because neither treatment has adverse effects, or that treatments adversely affect outcomes in different but approximately equivalent ways. Ocular irritation and headaches may also arise from equivalent adverse effects; enucleation can cause socket damage [14] and PBR can cause damage to extraocular structures, such as eyelids, canaliculi and the lacrimal gland [9]. Enucleation may adversely affect driving owing to loss of depth perception, and PBR owing to diminished visual acuity. It is unclear as to whether treatment modalities did not differentially affect driving or whether patients did experience driving difficulties after one or the other treatments and simply stopped driving.

It might be expected that enucleation would increase concerns about appearance, as dissatisfaction with prostheses is relatively common [13]. This indeed was the case before statistical adjustment, but no differences in appearance concerns were observed after adjustment. Thus, treatment differences are probably attributable to pre-treatment differences between treatment groups, and unlikely to be a consequence of enucleation. The equivalence of appearance concerns between enucleation and PBR may reflect either recent advances in the development of implants and prostheses $[14,26]$ or a generally low concern about appearance in our sample of older patients [25].

Some patients may opt for enucleation to avoid worry about recurrence. Unlike breast cancer, where women achieve reductions of fear and worry after mastectomy [27], enucleation did not differentially reduce worry compared to PBR. Enucleated patients were more likely to have monosomy 3 , although evidence suggests that this is not necessarily associated with worry about recurrence [15]. Enucleation can reduce the small probability of local cancer recurrence, but we have no evidence that it reduces patients' subjective worry about recurrence.

This study has several limitations. Owing to initial disparity in patient and tumour characteristics, it was unfeasible to compare our findings with patient groups who had neither enucleation nor PBR. Thus, we cannot comment on how each procedure affects patients in absolute terms. Second, patients could not be randomised to treatment modality. Although we used a series of statistical adjustments, we cannot exclude the possibility of confounding. Nonetheless, findings are not confounded by pre-treatment group differences in demographic variables, unrelated illnesses, tumour size or chromosome 3 status, which were statistically controlled. We used a relatively small sample and had 53.9\% initial recruitment and 59.3\% retention, although retention analysis showed retention to be unbiased. Last, questionnaires were self-administered without supervision, which might lead to greater error than professionally-administered scales.

Findings of this study can help clinicians and patients to make informed decisions between enucleation and PBR. First, enucleation can lead to greater functional difficulties associated with depth perception tasks, although this difference between the treatments seemed to abate after 12 months. PBR on the other hand is more likely to lead to patient-reported difficulties with visual impairments, experienced as loss of vision or visual problems in the treated eye affecting vision in the fellow eye. This is problematic for reading. Secondly, patients can be informed that enucleation will reduce the possibility of local recurrence in the affected eye, but it is unlikely to help them to reduce worry about recurrence. Finally, choice of treatment modality is unlikely to cause greater difficulties associated with ocular irritation, appearance or driving.

\section{Summary}

\section{What was known before}

- Some UMs can be treated by enucleation or PBR. To make effective decisions about which treatment to use, clinicians and patients need to understand potential adverse outcomes of each. Adverse clinical effects of each procedure are widely understood, but it is not known how patients experience these effects.

\section{What this study adds}

- Enucleation was associated with transient functional problems on tasks requiring binocular vision. PBR was associated with greater impairments of central and peripheral vision, and reading difficulties. No differences in adverse effects were reported for driving, ocular irritation, headaches, appearance concerns or WREC. Findings can help patients and clinicians to make better informed decisions between enucleation and PBR.

Acknowledgements We thank Nicola Longrigg and Gary Cheetham of Liverpool Ocular Oncology Centre: St. Paul's Eye Unit, Royal Liverpool and Broadgreen University Hospitals Trust for their assistance with data management.

\section{Compliance with ethical standards}

Conflict of interest The authors declare that they have no conflict of interest.

Publisher's note: Springer Nature remains neutral with regard to jurisdictional claims in published maps and institutional affiliations. 


\section{References}

1. Virgili G, Gatta G, Ciccollao L, Capocaccia R, Biggeri A, Crocetti E, et al. Incidence of uveal melanoma in Europe. Ophthlamology. 2007;114:2309-15.

2. Damato B. Does ocular treatment of uveal melanoma influence survival? Br J Cancer. 2010;103:285-90.

3. Mosci D, Baldo Lanza F, Barla A, Mosci S, Herault J, Anselmi L, et al. Comparison of clinical outcomes for patients with large choroidal melanoma after primary treatment with enucleation or proton beam radiotherapy. Opthlamologica. 2012;227:190-6.

4. Damato B, Heimann H. Personalized treatment of uveal melanoma. Eye. 2013;27:172-9.

5. Damato B, Lecuona K. Conservation of eyes with choroidal melanoma by a multimodality approach to treatment: an audit of 1632 patients. Ophthalmology. 2004;111:977-83.

6. Hope-Stone L, Brown SL, Heimann H, Damato B, Salmon P. Phantom eye syndrome: patient experiences after enucleation for uveal melanoma. Ophthalmology. 2015;122:1585-90.

7. Caujolle JP, Paoli V, Chamorey E, Maschi C, Baillif S, Herault J, et al. Local recurrence after uveal melanoma proton beam therapy: Recurrence types and prognostic consequences. Int J Radiat Oncol. 2013;85:1218-24.

8. Papakostas TD, Lane AM, Morrison M, Evangelos SG, Kim IK. Long-term outcomes after proton beam irradiation in patients with large choroidal melanomas. JAMA Ophthalmol. 2017;135:1191-6.

9. Damato B, Kacperek A, Chopra M, Campbell IR, Errington RD. Proton beam radiotherapy of choroidal melanoma: the liverpoolclatterbridge experience. Int J Radiat Oncol. 2005;62:1405-11.

10. COMS Quality of Life Study Group. Quality of Life assessment in Collaborative Ocular melanoma Study: study design and methods. COMS QOLs Report No1. Ophthal Epidemiol. 1999;6:5-17.

11. Kujala E, Mäkitie T, Kivelä T. Very long-term prognosis of patients with malignant uveal melanoma. Invest Ophthalmol Vis Sci. 2003;44:4651-9.

12. Damato B, Eleuteri A, Taktak AF, Coupland S. Estimating prognosis for survival after treatment of choroidal melanoma. Prog Retin Eye Res. 2011;30:285-95.

13. Rasmussen MLR. The eye amputated - consequences of eye amputation with emphasis on clinical aspects, phantom eye syndrome and quality of life. Acta Ophthalmol. 2010;88:1-26.

14. Bohman E, Roed Rassmusen ML, Kopp ED. Pain and discomfort in the anophthalmic socket. Curr Opin Ophthalmol. 2014;25:455-60.

15. Brown SL, Hope-Stone L, Heimann H, Salmon P. Predictors of anxiety and depression two years following treatment in uveal melanoma survivors. Psycho-Oncology. 2018;27:1727-34.
16. Brown SL, Whiting D, Fielden HG, Saini P, Beesley H, Holcombe C, et al. Qualitative analysis of how patients decide that they want risk-reducing mastectomy, and the implications for surgeons in responding to emotionally-motivated patient requests. PLoS ONE. 2017;12:e0178392.

17. Beesley H, Ullmer H, Holcombe C, Salmon P. How patients evaluate breast reconstruction after mastectomy, and why their evaluation often differs from that of their clinicians. J Plast Reconstr Aes. 2012;65:1064-71.

18. Damato B, Hope-Stone L, Cooper B, Brown S, Salmon P, Heimann $\mathrm{H}$, et al. Patient-reported outcomes and quality of life after treatment of choroidal melanoma: A comparison of enucleation vs radiotherapy in 1596 patients. Am J Ophthalmol. 2018;193:230-51.

19. Hope-Stone L, Brown SL, Heimann H, Damato B, Salmon P. Two-year patient-reported outcomes following treatment of uveal melanoma. Eye. 2016;30:1598-605.

20. Dogrusoz M, Jager MJ. Genetic prognostication in uveal melanoma. Acta Ophthalmol. 2018;96:331-47.

21. Brandberg Y, Damato B, Kivelä T, Kock E, Seregard S. The EORTC ophthalmic oncology quality of life questionnaire module (EORTC QLQ-OPT30). Development and pre-testing (Phase IIII). Eye. 2004;18:283-9.

22. Chmielowska K, Tomaszewski KA, Pogrzebielski A, Brandberg Y, Romanowska-Dixon B. Translation and validation of the Polish version of the EORTC QLQ-OPT30 module for the assessment of health-related quality of life in patients with uveal melanoma. Eur J Cancer Care. 2013;22:88-96.

23. Collaborative Ocular Melanoma Study-Quality of Life Study, G. Quality of life after iodine 125 brachytherapy vs enucleation for choroidal melanoma: 5-year results from the Collaborative Ocular Melanoma Study: COMS QOLS Report No. 3. Arch Ophthalmol. 2006; 124:226-38

24. Steeves JKE, González EG, Steinbach MJ. Vision with one eye: a review of visual function following unilateral enucleation. Spat Vis. 2008;21:509-29.

25. Pine NS, de Terte I, Pine KR. An investigation into discharge, visual perception, and appearance concerns of prosthetic eye wearers. Orbit. 2017;36:401-6.

26. Ho VW, Hussain RN, Czanner G, Sen J, Heimann H, Damato BE. Porous versus nonporous orbital implants after enucleation for uveal melanoma: a randomized study. Ophthalmic Plast Reconstr Surg. 2017;33:452-8.

27. Heiniger L, Butow PN, Coll J, Bullen T, Wilson J, Baylock B, et al. Long-term outcomes of risk-reducing surgery in unaffected women at increased familial risk of breast and/or ovarian cancer. Fam Cancer. 2015;14:105-15. 